\title{
First-line chemotherapy with liposomal doxorubicin plus cisplatin for patients with advanced malignant pleural mesothelioma: phase II trial
}

\author{
Ó Arrieta*,1,2, LA Medina ${ }^{3,4}$, E Estrada-Lobato ${ }^{5}$, N Hernández-Pedro², G Villanueva-Rodríguez ${ }^{2}$, L Martínez- \\ Barrera $^{6}$, EO Macedo', V López-Rodríguez ${ }^{3}$, D Motola-Kuba' and JF Corona-Cruz' \\ 'Clinica de Tumores Torácicos, San Fernando \#22, Colonia Sección XVI, Tlalpan, México City 14080, México; ${ }^{2}$ Laboratorio de Oncología Experimental, \\ Instituto Nacional de Cancerología (INCan), San Fernando \#22, Colonia Sección XVI, Tlalpan, México City 14080, México; ${ }^{3}$ Instituto de Física, \\ Universidad Nacional Autónoma de México (UNAM), México City, México; ${ }^{4}$ Unidad de Investigación Biomédica en Cáncer, \\ INCan-UNAM, México City, México; ${ }^{5}$ Departamento de Medicina Nuclear, INCan, México City, México; ${ }^{6}$ Departamento de Oncología, Instituto Nacional \\ de Enfermedades Respiratorias (INER), México City, México
}

\begin{abstract}
BACKGROUND: Chemotherapy based on platinum is the standard treatment for unresectable malignant pleural mesothelioma (MPM). Liposomal doxorubicin (LD) consists of pegylated phospholipid vesicles that encapsulate doxorubicin-enhancing liposome deposition in the tumour. We evaluated the toxicity profile and anti-tumour activity of cisplatin plus LD in untreated patients with MPM, as well as ${ }^{99 \mathrm{~m}}$ Tc-LD distribution in MPM lesions after chemotherapy administration.

METHODS: A total of 38 patients with non-resectable MPM received LD $40 \mathrm{mg} \mathrm{m}^{-2}$ and cisplatin $60 \mathrm{mg} \mathrm{m}^{-2}$ every 21 days. Gamma camera images of ${ }^{99 \mathrm{~m}}$ Tc-LD were acquired to evaluate LD accumulation in measurable tumour tissue. The study was registered in Clinical Trials (NCT00886028).

RESULTS: In all, $72 \%$ of patients were stage III and 28\% were stage IV. Eighty four percent and I $6 \%$ have high and low risk acording EORTC respectively. The median time to progression was 4.6 months (95\% confidence interval (95\% Cl: $3.4-5.9$ months), and median overall survival (OS) was 19.6 months (I5.2-37.2 months). Patients that responded to chemotherapy treatment had better survival than patients who did not. Functional physical scales, dysnea, cough, and chest/arm pain demonstrated improvement. The accumulation ratio of LD in tumour and soft tissues vs liver was $0.78 \pm 0.16$ and $0.29 \pm 0.09$, respectively. After I h of administration, LD uptake in tumour tissue was higher than in soft tissue $(P<0.001)$.

CONCLUSION: The combination of LD and cisplatin results in an active therapeutic regimen for unresectable MPM, with an acceptable toxicity profile and improvement in quality of life. ${ }^{99 \mathrm{~m}} \mathrm{Tc}-\mathrm{LD}$ showed higher levels of tumour uptake as compared with surrounding tissues.

British Journal of Cancer (2012) 106, 1027-1032. doi:I0.1038/bjc.2012.44 www.bjcancer.com

Published online 21 February 2012

(c) 2012 Cancer Research UK
\end{abstract}

Keywords: malignant pleural mesothelioma; liposomal doxorubicin; quallity life; cisplatin; Phase II; LD radiolabelling

Malignant pleural mesothelioma (MPM) is a primary tumour arising from the mesothelial cells of the pleura and is associated with aggressive local tumour invasion and poor prognosis (Connelly et al, 1987). This represents a serious health problem as the worldwide incidence continues to increase in the Western Europe and the United States (Antman, 1980). In the United States $\sim 2300$ new cases are diagnosed annually, increasing up to $50 \%$ the prevalence rates in the last 10 years (Price, 1997). In the United Kingdom, is responsible for 2700-3000 deaths each year and a prevalence increase is estimated until 2020 (Peto et al, 1995). In Mexico, it is difficult to determine the real incidence of MPM due to disease under diagnosis and non-registration; this results in only 1500 registered cases in 15 years (Prevalencia del

*Correspondence: Dr Ó Arrieta; E-mail: ogar@servidor.unam.mx Received 3 November 2011; revised 23 January 2012; accepted 24 January 2012; published online 21 February 2012 mesotelioma pleural en México, 2007). Eighty percent of patients with MPM have a history of asbestos exposure (Ashcroft, 1973; Nicholson et al, 1982) other risk factors include history of thoracic radiation (Hodgson et al, 2007) and possibly exposure to Simian virus 40 (Rizzo et al, 1999; Cristaudo et al, 2005). There are three main histological subtypes of MPM: epithelial, sarcomatoid, and mixed. The epithelial type is the most common and represents $50 \%$ of all cases, whereas sarcomatoid is the most aggressive type and represents $15 \%$ of all cases (Winslow and Taylor, 1960).

Surgery is the principal modality in the curative intent treatment of patients with MPM and would be administered with only a palliative goal or, especially in those with localised disease. The procedures included among these surgeries are: pleurectomy and decortication; and extrapleural pneumonectomy (EPP; Yan et al, 2009). Extrapleural pneumonectomy consists of cytoreductive surgery on pleural surfaces while preserving the lung, this procedure is recommended for patients without tumour involvement of lung parenchyma or soft tissues; morbidity is $10 \%$ and the 
mortality is $<1 \%$ (Baldini et al, 1997). To date, there is no consensus concerning the role of the surgery in MPM (de Perrot et al, 2009). Moroever, some studies suggested that the radical treatment has a better prognostic (Treasure et al, 2011). As a consequence, several studies have explored the use of multimodality therapy, including adjuvant and neoadjuvant chemotherapy, even in patients with resectable disease (Weder et al, 2007).

For non-resectable advanced MPM, systemic chemotherapy has shown to improve disease control and to diminish associated symptoms. The use of single-chemotherapy agents has reported an overall response rate (RR) in the range of $10-20 \%$ (Kindler, 2008; Ray and Kindler, 2009). Meta-analysis has demonstrated that the most beneficial drug in advanced MPM treatment is cisplatin (Berghmans et al, 2002). Recent studies have reported that use of combined chemotherapy exhibited a higher RR compared with single-agent chemotherapies (Ray and Kindler, 2009). The combination of cisplatin and pemetrexed was established as first-line standard treatment after the results of a phase III trial that compared the combination $v s$ cisplatin alone and reported higher median overall survival (OS) (Vogelzang et al, 2003).

Doxorubicin has demonstrated to be an active drug in the treatment of advanced MPM in phase II studies, as well as the combination with cisplatin, with RR of $25-46 \%$ and median OS of 8.8-10 months. Unfortunately, long-term use of doxorubicin is limited because of its toxicity profile such as grades 3 and 4 myelosuppression, mucositis, nausea, vomiting, alopecia, and cardiotoxicity (Henss et al, 1988; Ardizzoni et al, 1991; Chahinian et al, 1993).

Liposomal doxorubicin (LD), doxorubicin hydrochloride encapsulated in liposomes coated with methoxy polyethylene glycol, has shown diminished uptake by the reticule-endothelial system, a longer half-life, a different toxicity profile from that of nonpolyethylene glycolylated liposomes, and theoretically increases liposomal deposition in tumour tissue. A phase II European Organisation for Research and Treatment of Cancer (EORTC) study that evaluated LD $\left(45 \mathrm{mg} \mathrm{m}^{-2}\right)$ as monotherapy, showed a median survival of 13 months and only mild toxicity; the EORTC members concluded that there are good reasons for evaluating this drug in combination with other cytostatic drugs (Baas et al, 2000).

We have conducted a trial to evaluate the safety, progressionfree survival (PFS), OS, and RR of LD plus cisplatin in patients with advanced MPM, as well as ${ }^{99 m} \mathrm{Tc}-\mathrm{LD}$ distribution in MPM lesions after chemotherapy administration.

\section{PATIENTS AND METHODS}

\section{Patients}

In this Phase II study, patients with histologically confirmed stage IIIB/IV MPM were included. All biopsies were centrally reviewed by an expert panel of oncology Pathologists. A set of immunohistochemical stains was used in all cases. Patients had the following Inlcusion criteria: Eastern Cooperative Oncology Group performance status of $0-2$; no prior chemotherapy treatment; age $\geqslant 18$ years; normal haematological, renal and hepatic functions (white blood cell count $\geqslant 1500 \mathrm{~mm}^{-3}$, haemoglobin $\geqslant 10.0 \mathrm{~g} \mathrm{dl}^{-1}$, platelet count $\geqslant 100000 \mathrm{~mm}^{-3}$, total bilirubin $\leqslant 1.5 \mathrm{mg} \mathrm{dl}^{-1}$, aspartate aminotransferase $\leqslant 2.0 \mathrm{mg} \mathrm{dl}^{-1}$ normal upper limit, creatinine $\leqslant 1.5 \mathrm{mg} \mathrm{dl}^{-1}$ ); measurable disease according to the modified Response Evaluation Criteria in Solid Tumours (RECIST) gauge for assessment of response in MPM (Byrne and Nowak, 2004) and life expectancy $>12$ weeks. A complete medical history and physical examination including complete blood count with differential and platelet count, biochemical profile, urinalysis, electrocardiogram, and axial computed tomography (CT) of the chest and abdomen were obtained. The study protocol was approved by the local Institutional Scientific and Bioethics

Committee (007/024/OMI-CV/304/06) and was registered in clinical trials (NCT00886028). All patients signed written informed consent.

\section{LD radiolabelling and scintigraphic imaging procedure}

The individual dose of LD (Doxopeg, Asofarma-México, México $\mathrm{DF}$, Mexico) was radiolabeled with ${ }^{99 \mathrm{~m}} \mathrm{Tc}$ using SNS/S N,N-Bis(2mercapto-ethyl)- $N^{\prime}, N^{\prime}$-diethyl-ethylenediamine (BMEDA) as described previously by Bao et al (2004). The labelling efficiency of the ${ }^{99 \mathrm{~m}} \mathrm{Tc}$-BMEDA was calculated by utilising the activity in ${ }^{99 \mathrm{~m}} \mathrm{Tc}$ LD before and after separation in the column. To evaluate biodistribution and accumulation of ${ }^{99 \mathrm{~m}} \mathrm{Tc}-\mathrm{LD}$ in measurable tumour tissue, $1 \mathrm{~h}$ after the infusion, the patient underwent planar whole-body imaging $\left(10 \mathrm{~cm} \mathrm{~min}^{-1}, 1056 \times 1056\right.$ matrix, no zooming) and a thorax (single-photon emission CT (SPECT) (64 frames $30 \mathrm{~s}^{-1}$; $64 \times 64$ matrix, no zooming) using a double-head SPECT camera (e-Cam, Siemens, Erlangen, Germany). Singlephoton emission CT images were fused with low-dose CT images (Sensation 16, Siemens) for anatomical reference. Standard regions-of-interest (ROI) were drawn on the planar and SPECT images in tumour, soft tissue, and the liver to evaluate ${ }^{99 \mathrm{~m}} \mathrm{Tc}-\mathrm{LD}$ accumulation. Figure 1 depicts ROI on whole-body images and the relationship between them. Uptake index was calculated as the ratio of the number of counts in ROIs in tumour and soft tissue $v s$ liver.

\section{Chemotherapy administration}

Patients received LD $40 \mathrm{mg} \mathrm{m}^{-2}$ in $60 \mathrm{~min}$ and cisplatin $60 \mathrm{mg} \mathrm{m}^{-2}$ in a 3 -h infusion on day 1 of every 21 days cycle, patients were treated for a maximum of six cycles and all patients received antiemetic therapy with ondansetron, dexamethasone, and aprepitant. Radiolabeled LD was administered only in the first cycle to verify LD accumulation in tumour tissue.

\section{Toxicity evaluation}

Physical examination and laboratory tests were performed before every cycle. The National Cancer Institute Common Toxicity Criteria was used to evaluate toxicity. Dose reductions or delayed chemotherapy was permitted when toxicity grades 3-4 did not resolve after 1 week.

A

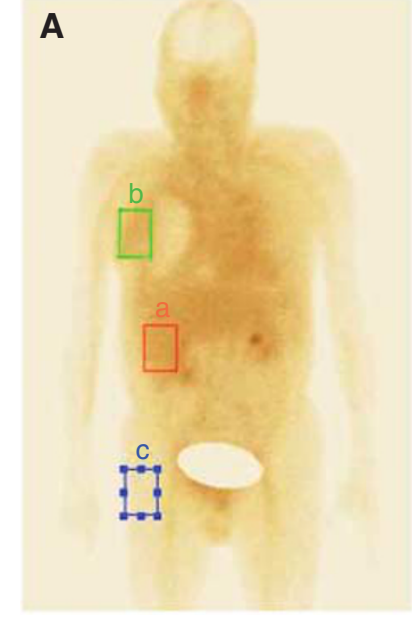

Figure I (A) Whole-body scan acquired I h after ${ }^{99} \mathrm{~m}$ Tc-LD injection The image shows the ROls as described in the text by the (a) Liver, (b) Tumoural tissue, and (c) Soft tissue (background area). Single-photon emission CT images in figures $(\mathbf{B})$ and $(\mathbf{C})$ show ${ }^{99 \mathrm{~m} T \mathrm{~T}-L D}$ uptake in tumour tissue (arrows). 


\section{Response assessment and follow-up}

Response assessment was determined every two cycles according to the modified RECIST criteria (Byrne and Nowak, 2004). Patients with chemotherapy response were evaluated by a Thoracic Surgeon (JFC-C) to determine whether they were candidates for surgical treatment after four cycles of chemotherapy; if surgery was not possible, chemotherapy continued up to six cycles until disease progression, high-grade toxicity, or withdrawal of informed consent. Patients without disease progression during chemotherapy treatment were followed-up with axial CT every 2 months to determine PFS.

\section{Quality of life}

The 30-item EORTC Quality of Life (QoL) Questionnaire (EORTC QLQ-C30) version 3.0 (Spanish version) was used in this trial. EORTC QLQ v3 consists of five multi-item functional scales, three symptom scales, a global health status/QoL scale, and six single items. Transformation of scores was performed according to the instructions in the manual. Scores on all scales and single items could range from 0 to 100 points. Higher scores on functional and global health status QoL scales reflect better functioning. On symptom scales, higher scores mean more symptoms or problems. Quality of life questionnaires were filled out 1 day before the first chemotherapy cycle and after finishing four cycles of chemotherapy.

\section{Statistical analysis}

Continuous variables were descriptive with means, medians and s.d.; variable categories were proportions and 95\% confidence intervals (95\% CIs). Inferential comparisons were conducted by means of the Student's $t$ - or the Mann-Whitney $U$-test according to data distribution (normal and non-normal, respectively) determined by the Kolmogorov-Smirnov test. The $\chi^{2}$ or the Fisher exact test was used to evaluate significance among categorical variables. Comparisons between QoL were performed before and after the second cycle of chemotherapy and were analysed with the Wilcoxon-related samples test. When the scale showed differences $>10 \%$, these were considered as clinically significant. Statistical significance was determined as a $P$-value $(P \leqslant 0.05)$ with a two-tailed test. Progression-free survival and OS were determined from day of initiation of chemotherapy until progression and until death or until last day of follow-up, respectively, and were analysed by the Kaplan-Meier test, while comparisons among patients with or without response were analysed with the log-rank test. The SPSS version 15 (SPSS Inc., Chicago, IL, USA) software package was utilised for data analysis.

\section{RESULTS}

\section{Population of patients}

This trial included patients from two thoracic oncology reference centres in Mexico City (Instituto Nacional de Cancerología (INCan) and Instituto Nacional de Enfermedades Respiratorias). From September 2006 to September 2009, 38 consecutive patients with stage III/IV MPM were included. All included patients had unresectable disease. The median age at diagnosis was $60.1 \pm 11.5$ years. Males represented the majority (73.6\%) of patients. Seventy four percent of patients had epithelioid histology. A total of $84.22 \%$ of patients were classified as high-risk according to the EORTC risk classification (Table 1).

\section{Response rate}

Two patients were unable to be valuable after treatment because of one mortality and the other unable to make the study to asses
Table I Clinical characteristics of patients

\begin{tabular}{|c|c|c|}
\hline Characteristics & & $\%$ \\
\hline Patients enrolled & 38 & 100 \\
\hline \multicolumn{3}{|l|}{ Gender } \\
\hline Male & 29 & 76.6 \\
\hline Woman & 9 & 23.7 \\
\hline \multicolumn{3}{|l|}{ Age (years) } \\
\hline Median \pm s.d. & $60.1 \pm 11.5$ & \\
\hline \multicolumn{3}{|l|}{ Smoking status } \\
\hline Non-smokers & 16 & 42.1 \\
\hline Smokers & 22 & 57.9 \\
\hline Asbestos & 23 & 60.5 \\
\hline Wood smoke & 12 & 31.6 \\
\hline \multicolumn{3}{|l|}{ Stage at enrollment } \\
\hline IIIB & 27 & 72 \\
\hline IV & 11 & 28 \\
\hline \multicolumn{3}{|l|}{ Histology } \\
\hline Epithelial & 28 & 73.3 \\
\hline Sarcomatoid & 6 & 15.4 \\
\hline Biphasic & 4 & 10.3 \\
\hline \multicolumn{3}{|l|}{ ECOG-PS } \\
\hline 0 & 4 & 10.3 \\
\hline । & 24 & 61.5 \\
\hline 2 & 10 & 25.6 \\
\hline Albumin $g \mathrm{dl}^{-1}$ & $2.8 \pm 0.5$ & \\
\hline Median received treatment & 4 & \\
\hline Delayed treatment & 16 & 42.1 \\
\hline \multicolumn{3}{|l|}{ Response } \\
\hline Partial response & 14 & 38.9 \\
\hline Stable disease & 15 & 41.6 \\
\hline Progression & 7 & 19.4 \\
\hline \multicolumn{3}{|l|}{ EORTC } \\
\hline Good-prognosis group & 6 & 15.78 \\
\hline Poor-prognosis group & 32 & 84.22 \\
\hline
\end{tabular}

Abbreviations: ECOG-PS = Eastern Cooperative Oncology Group-performance status; EORTC = European Organisation of Research for Cancer; Karnofsky= Karnofsky performance status.

response. Partial responses were observed in 38.9\% (14/36; 95\% CI, $22.97-54.82)$ of patients, stable disease in $41.6 \%(15 / 36 ; 95 \% \mathrm{CI}$, $25.5-57.7)$, and disease progression in $19.4 \%$ (7/36, 95\% CI, 6.48 32.31). No complete response was observed. Patients who responded to chemotherapy were re-evaluated by the Thoracic Surgeons department. From all patients with a response to treatment six patients were eligible for surgery, but only three patients had complete cytoreductive surgery.

\section{Toxicity evaluation}

Severe acute toxic effects are listed in Table 2. There were no treatment-related deaths and only one patient withdrew from treatment secondary to side effects (neutropaenia without recovery). Two patients had an increase of creatinine levels and required a change from cisplatin to carboplatin. The most commonly experienced side effects were nausea and vomiting in $36.9 \%$ and hand-foot syndrome in 6 patients $(15.8 \%)$. Toxicity grade $\geqslant 2$ comprised leukopaenia (13.2\%), neutropaenia (7.9\%), nausea and vomiting $(36.9 \%)$, and anaemia $(21.1 \%)$, in addition to hand-foot syndrome (7.9\%). 
Table 2 Toxic effects

\begin{tabular}{lcc}
\hline Toxic effect & $\begin{array}{c}\text { Grades } \geqslant \mathbf{2} \\
\text { no. of patients }\end{array}$ & \% \\
\hline Anemia & 22 & 57.9 \\
Nausea and vomiting (non-haematological) & 14 & 36.9 \\
Lymphopaenia & 8 & 21.1 \\
Thrombocytopaenia & 8 & 21.1 \\
Fatigue (non-haematological) & 8 & 21.1 \\
Leukopaenia & 5 & 13.2 \\
Anorexia (non-haematological) & 5 & 13.2 \\
Neuropathy (non-haematological) & 5 & 13.2 \\
Neutropaenia & 3 & 7.9 \\
Hand-foot syndrome & 3 & 7.9 \\
Creatinine & 2 & 5.3 \\
Constipation (non-haematological) & 2 & 5.3 \\
Diarrhoea (non-haematological) & 1 & 2.6 \\
\hline
\end{tabular}
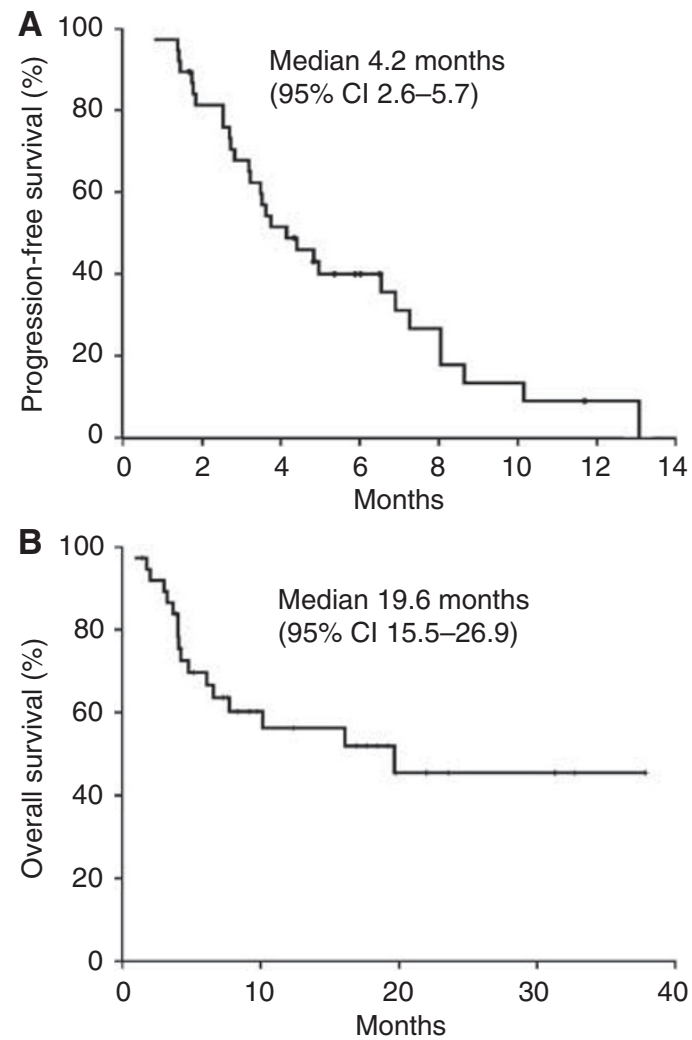

Figure 2 Kaplan-Meier of patients treated with chemotherapy and LD. (A) progression-free survival and (B) overall survival.

\section{Survival outcomes}

The median follow-up was $11.6 \pm 9$ months. Median and mean number of received cycles of treatment were 4 and 3.5 cycles, respectively. Median time to disease progression was 4.2 months (Figure 2A; 95\% CI, 3.4-5.9 months) and median OS was 19.6 months (95\% CI, 15.2-37.2 months; Figure 1B). Patients who responded to the treatment had better survival than patients who did not. Patients who did not respond to chemotherapy had a median survival of 7.7 months (95\% CI, 2.17-38.18 months) and those who responded did not reach OS at time of analysis $(P=0.06)$. After progression to LD plus cisplatin, $35(92.1 \%)$ and $27(71.1 \%)$ patients received second-line chemotherapy based on pemetrexed, gemcitabine, or vinorelbine.

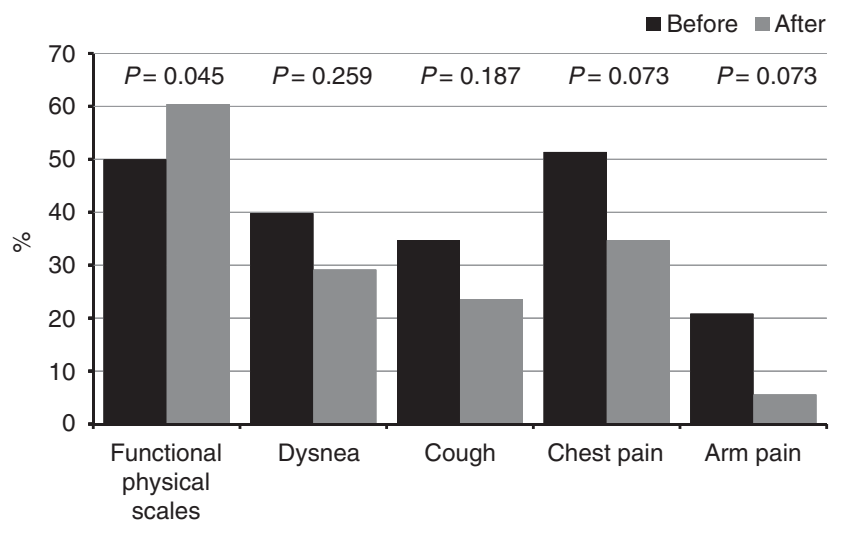

Figure 3 Percent of the functional physical scales, the dysnea, the cough, the chest pain and the arm pain before and after of the treatment.

\section{Quality of life (QoL)}

QoL exhibited changes before and after two cycles of chemotherapy in functional physical scale, dysnea, cough, and chest-arm pain. Functional physical scale was the only one with statistical significant changes $(P=0.045)$. However, dyspnoea, cough, chest pain, and arm pain decrease $>10 \%$, being statistically significant (Figure 3). Emotional, cognitive, social, fatigue, insomnia, hyporexia, constipation, diarrhoea, financial difficulties, haemoptysis, mucositis, dysphagia, and alopecia did not demonstrate statistical differences.

\section{Tissue distribution of ${ }^{99 \mathrm{~m}} \mathrm{Tc}-\mathrm{LD}$}

The ${ }^{99}$ Tc-LD labelling efficiency was $48 \pm 12 \%$. Scintigraphical images (Figures $1 \mathrm{~B}$ and $\mathrm{C}$ ) depicted an uptake index of radiolabeled LD in the tumour tissue of $0.78 \pm 0.16 \%$. In $80 \%$ of the imaged patients, tumour uptake index of ${ }^{99 \mathrm{~m}} \mathrm{Tc}-\mathrm{LD}$ at $1 \mathrm{~h}$ after its administration was higher than uptake index in soft tissue $(0.29 \pm 0.09 \% ; P<0.001)$.

\section{DISCUSSION}

Advanced MPM is a poor-prognosis tumour with a median OS of 4-13 months in patients without treatment and of 6-18 months in patients with palliative chemotherapy. In a meta-analysis conducted in 2002, cisplatin showed to be the most important chemotherapy drug for treatment of advanced MPM (Berghmans et al, 2002). After this study, the combination of cisplatin and new generation drugs has been investigated to determine its beneficial role in these patients. Only pemetrexed and raltitrexed in combination with cisplatin have been studied in phase III trials, showing better OS compared with cisplatin alone (Vogelzang et al, 2003; van Meerbeeck et al, 2005; Kelly et al, 2011). The combination of cisplatin and pemetrexed was established as first-line standard treatment after the results of a phase III trial that compared the combination $v s$ cisplatin alone and reported higher median OS (12.1 vs 9.3 months; $P=0.020$ ), longer median time to disease progression (5.7 vs 3.9 months; $P=0.001)$, and higher RR $(41.3 \%$ vs $16.7 \% ; P=0.0001)$. In our institution the majority of patients, do not have access to social security or medical insurance. Because of pemetrexed costs is difficult for patients to have it as a standard care. Combinations of cisplatin with other effective drugs (vinorelbine, gemcitabine) have not, to our knowledge, been studied in phase III trials (Sorensen et al, 2008).

Doxorubicin have shown efficacy against mesothelioma (Antman, 1980). The concentration of LD in tumours is result of 
the enhanced permeability and retention effect, as a consequence of a leaky microvasculature and impaired lymphatics supporting the tumour area Drummond et al, 1999). The movement of LD into the mesothelioma interstitium its probably by extravasation through the discontinuous endothelium of the mesothelioma microvasculature. Once in the tumour, LD is mainly localised in the interstitum surrounding tumour cells (Figure 1). In the present phase II study, we evaluated the antitumour activity of a combination with LD plus cisplatin (LD/P) in patients with advanced MPM. Our results showed that this combination (LD/P) is active, with partial response in $38.9 \%$ and stable disease in $41.6 \%$ of patients, although the majority of patients have poor-prognosis characteristics $(84.22 \%)$ according to the EORTC risk classification. In addition, toxicity was manageable, only one patient withdrew from treatment due to side effects, and there were no treatment-related deaths. Quality of life showed changes before and after the second cycle of chemotherapy in functional physical scale, dysnea, cough, and chest-arm pain. Liposomal doxorubicin is much less toxic (Uziely et al, 1995), and response had been reported in mesothelioma in $7 \%$ of patients as monotherapy with median time to tumour progression and survival of 5 and 12 months (Hillerdal et al, 2008a, b), respectively. Antitumour activity of LD as monotherapy was noted in a small phase II study in which 15 patients with advanced MPM were treated with LD $55 \mathrm{mg} \mathrm{m}^{-2}$ every 4 weeks; 4 of the 15 evaluable patients showed objective response $(26 \%)$ and a median OS of 13 months; QoL remained good during the study and no significant toxicity was observed, suggesting positive activity of this drug in MPM (Skubitz, 2002). Other phase II study published by the EORTC that included 33 patients with MPM evaluated LD as monotherapy with $6 \%$ of RRs, and similar to the previous trial, median survival was 13 months (Baas et al, 2000). The Nordic Mesothelioma Group investigated a combination of $\mathrm{LD}$, gemcitabine, and carboplatin in MPM in a phase II trial, reporting $32.4 \%$ of RRs with median time to progression and OS of 8.6 and 13 months respectively, however, for patients with epithelioid subtype, median OS was 17 months (Hillerdal et al, 2008a,b). Similar to our results, this group reported a correlation between response and survival.

Delivery and penetration of the chemotherapy drugs into tumours are limited by a number of factors related with altered stromal composition in neoplastic tissue. Mesotheliomas might contain large amounts of fibrous tissue, which might reduce drug penetration. We also evaluated ${ }^{99 \mathrm{~m}} \mathrm{Tc}-\mathrm{LD}$ accumulation in MPM lesions after chemotherapy administration. As reported previously by several authors, in our study LD has shown a diminished uptake by the reticulo-endothelial system, a longer half-life, and a different toxicity profile than doxorubicin, the results have shown an increased liposomal deposition in tumour tissue, resulting in antitumoural effectiveness (Northfelt et al, 1996). It has been established that a mechanism of resistance of solid tumours to chemotherapy may comprise limited penetration of anticancer drugs into tumour tissue (Tannock et al, 2002). In our study, we found a similar distribution of radiolabeled LD in tumour tissue as compared with liver (uptake index $0.78 \pm 0.16 \%$ ); the latter is the primary liposome uptake site. However, LD uptake was significantly higher in tumour cells as compared with soft tissue. This result supports the antitumour activity of this treatment regimen (LD/P). A study in Kaposi's sarcoma patients treated with LD also shows a correlation between distribution and chemotherapy response as compared with doxorubicin (Castagneto et al, 2005).

In conclusion, the combination LD plus cisplatin showed to be an active combination for MPM treatment with acceptable toxicity profile.

Because this is a phase II study with a small number of patients, it is necessary to perform phase III studies that compare the LD/P against cisplatin/pemetrexed or cisplatin/raltitrexed to determine a standard of treatment in first line.

\section{ACKNOWLEDGEMENTS}

We are grateful to the nurses and the NMT staff of the Nuclear Medicine Department at INCan, especially Zeferino GranadosCosme, NMT, for his help during image acquisitions and Alma D Campos-Parra $(\mathrm{PhD})$ for his help to administrative support. This work was partly supported by the Consejo Nacional de Ciencia y Tecnologia, México (CONACyT-014147and CONACyT 044395). We also thank Asofarma de México, SA de CV for kindly providing part of Doxopeg to perform this study. Asofarma de México, SA de $\mathrm{CV}$ had no role in the design, collection, analysis, and interpretation of the data of this study, nor in the writing or the in decision to submit this manuscript for publication.

\section{REFERENCES}

Antman KH (1980) Current concepts: malignant mesothelioma. $N$ Engl Med 303: $200-202$

Ardizzoni A, Rosso R, Salvati F, Fusco V, Cinquegrana A, De Palma M, Serrano J, Pennucci MC, Soresi E, Crippa M, Gulisano M, Castagneto B, Scagliotti G, Rinaldi M (1991) Activity of doxorubicin and cisplatin combination chemotherapy in patients with diffuse malignant pleural mesothelioma. An Italian Lung Cancer Task Force (FONICAP) Phase II study. Cancer 67: 2984-2987

Ashcroft T (1973) Epidemiological and quantitative relationships between mesothelioma and asbestos on Tyneside. J Clin Pathol 26: 832-840

Baas P, van Meerbeeck J, Groen H, Schouwink H, Burgers S, Daamen S, Giaccone G (2000) Caelyx in malignant mesothelioma: a phase II EORTC study. Ann Oncol 11: 697-700

Baldini EH, Recht A, Strauss GM, DeCamp Jr MM, Swanson SJ, Liptay MJ, Mentzer SJ, Sugarbaker DJ (1997) Patterns of failure after trimodality therapy for malignant pleural mesothelioma. Ann Thorac Surg 63: $334-338$

Bao A, Goins B, Klipper R, Negrete G, Phillips WT (2004) Direct 99mTc labeling of pegylated liposomal doxorubicin (Doxil) for pharmacokinetic and non-invasive imaging studies. J Pharmacol Exp Ther 308: 419-425

Berghmans T, Paesmans M, Lalami Y, Louviaux I, Luce S, Mascaux C, Meert AP, Sculier JP (2002) Activity of chemotherapy and immunotherapy

on malignant mesothelioma: a systematic review of the literature with meta-analysis. Lung Cancer 38: 111-121

Byrne MJ, Nowak AK (2004) Modified RECIST criteria for assessment of response in malignant pleural mesothelioma. Ann Oncol 15: $257-260$

Castagneto B, Zai S, Dongiovanni D, Muzio A, Bretti S, Numico G, Botta M, Sinaccio G (2005) Cisplatin and gemcitabine in malignant pleural mesothelioma: a phase II study. J Clin Oncol 28: 223-226

Chahinian AP, Antman K, Goutsou M, Corson JM, Suzuki Y, Modeas C, Herndon II JE, Aisner J, Ellison RR, Leone L, Vogelzang NJ, Green MR (1993) Randomized phase II trial of cisplatin with mitomycin or doxorubicin for malignant mesothelioma by the Cancer and Leukemia Group B. J Clin Oncol 11: 1559-1565

Connelly RR, Spirtas R, Myers MH, Percy CL, Fraumeni Jr JF (1987) Demographic patterns for mesothelioma in the United States. J Natl Cancer Inst 78: $1053-1060$

Cristaudo A, Foddis R, Vivaldi A, Buselli R, Gattini V, Guglielmi G, Cosentino F, Ottenga F, Ciancia E, Libener R, Filiberti R, Neri M, Betta P, Tognon M, Mutti L, Puntoni R (2005) SV40 enhances the risk of malignant mesothelioma among people exposed to asbestos: a molecular epidemiologic case-control study. Cancer Res 65: 3049-3052

de Perrot M, Field R, Cho BC, Bezjak A, Anraku M, Burkes R, Roberts H, Tsao MS, Leighl N, Keshavjee S, Johnston MR (2009) Trimodality therapy with induction chemotherapy followed by extrapleural pneumonectomy 
and adjuvant high-dose hemithoracic radiation for malignant pleural mesothelioma. J Clin Oncol 27: 1413-1418

Drummond DC, Meyer O, Hong K, Kirpotin DB, Papahadjopoulos D (1999) Optimizing liposomes for delivery of chemotherapeutic agents to solid tumors. Pharmacol Rev 51: 691-743

Henss H, Fiebig HH, Schildge J, Arnold H, Hasse J (1988) Phase-II study with the combination of cisplatin and doxorubicin in advanced malignant mesothelioma of the pleura. Onkologie 11: 118-120

Hillerdal G, Sorensen JB, Sundstrom S, Vikström A, Hjerpe A (2008a) Treatment of malignant pleural mesothelioma with liposomized doxorubicine: prolonged time to progression and good survival. A Nordic study. Clin Respir J 2: 80-85

Hillerdal G, Sorensen JB, Sundstrom S, Riska H, Vikström A, Hjerpe A (2008b) Treatment of malignant pleural mesothelioma with carboplatin, liposomized doxorubicin, and gemcitabine: a phase II study. J Thorac Oncol 3: 1325-1331

Hodgson DC, Gilbert ES, Dores GM, Schonfeld SJ, Lynch CF, Storm H, Hall P, Langmark F, Pukkala E, Andersson M, Kaijser M, Joensuu H, Fosså SD, Travis LB (2007) Long-term solid cancer risk among 5-year survivors of Hodgkin's lymphoma. J Clin Oncol 25: 1489-1497

Kelly RJ, Sharon E, Hassan R (2011) Chemotherapy and targeted therapies for unresectable malignant mesothelioma. Lung Cancer 73: 256-263

Kindler HL (2008) Systemic treatments for mesothelioma: standard and novel. Curr Treat Options Oncol 9: 171-179

Nicholson WJ, Perkel G, Selikoff IJ (1982) Occupational exposure to asbestos: population at risk and projected mortality - 1980-2030. Am J Ind Med 3: $259-311$

Northfelt DW, Martin FJ, Working P, Volberding PA, Russell J, Newman M, Amantea MA, Kaplan LD (1996) Doxorubicin encapsulated in liposomes containing surface-bound polyethylene glycol: pharmacokinetics, tumor localization, and safety in patients with AIDS-related Kaposi's sarcoma. J Clin Pharmacol 36: 55-63

Peto J, Hodgson JT, Matthews FE, Jones JR (1995) Continuing increase in mesothelioma mortality in Britain. Lancet 345: 535-539

Prevalencia del mesotelioma pleural en México (2007) (accessed 25 July 2011, at http://www.imfimex.org/wpcontent/uploads/CONFERENCIA \%20OMAR\%20GARFIAS.pdf )

Price B (1997) Analysis of current trends in United States mesothelioma incidence. Am J Epidemiol 145: 211-218

Ray M, Kindler HL (2009) Malignant pleural mesothelioma: an update on biomarkers and treatment. Chest 136: 888-896

Rizzo P, Carbone M, Fisher SG, Matker C, Swinnen LJ, Powers A, Di Resta I, Alkan S, Pass HI, Fisher RI (1999) Simian virus 40 is present in most
United States human mesotheliomas, but it is rarely present in nonHodgkin's lymphoma. Chest 116(6 Suppl): 470S - 473S

Skubitz KM (2002) Phase II trial of pegylated-liposomal doxorubicin (Doxil) in mesothelioma. Cancer Invest 20: 693-699

Sorensen JB, Frank H, Palshof T (2008) Cisplatin and vinorelbine first-line chemotherapy in non-resectable malignant pleural mesothelioma. $\mathrm{Br} \mathrm{J}$ Cancer 99: $44-50$

Tannock IF, Lee CM, Tunggal JK, Cowan DS, Egorin MJ (2002) Limited penetration of anticancer drugs through tumor tissue: a potential cause of resistance of solid tumors to chemotherapy. Clin Cancer Res 8: 878-884

Treasure T, Lang-Lazdunski L, Waller D, Bliss JM, Tan C, Entwisle J, Snee M, O'Brien M, Thomas G, Senan S, O'Byrne K, Kilburn LS, Spicer J, Landau D, Edwards J, Coombes G, Darlison L, Peto J (2011) Extra-pleural pneumonectomy $v s$ no extra-pleural pneumonectomy for patients with malignant pleural mesothelioma: clinical outcomes of the Mesothelioma and Radical Surgery (MARS) randomised feasibility study. Lancet Oncol 12: $763-772$

Uziely B, Jeffers S, Isacson R, Kutsch K, Wei-Tsao D, Yehoshua Z, Libson E, Muggia FM, Gabizon A (1995) Liposomal doxorubicin: antitumor activity and unique toxicities during two complementary phase I studies. J Clin Oncol 13: $1777-1785$

van Meerbeeck JP, Gaafar R, Manegold C, Van Klaveren RJ, Van Marck EA, Vincent M, Legrand C, Bottomley A, Debruyne C, Giaccone G (2005) Randomized phase III study of cisplatin with or without raltitrexed in patients with malignant pleural mesothelioma: an intergroup study of the European Organisation for Research and Treatment of Cancer Lung Cancer Group and the National Cancer Institute of Canada. J Clin Oncol 23: $6881-6889$

Vogelzang NJ, Rusthoven JJ, Symanowski J, Denham C, Kaukel E, Ruffie P, Gatzemeier U, Boyer M, Emri S, Manegold C, Niyikiza C, Paoletti P (2003) Phase III study of pemetrexed in combination with cisplatin $v s$ cisplatin alone in patients with malignant pleural mesothelioma. J Clin Oncol 21: 2636-2644

Weder W, Stahel RA, Bernhard J, Bodis S, Vogt P, Ballabeni P, Lardinois D, Betticher D, Schmid R, Stupp R, Ris HB, Jermann M, Mingrone W, Roth AD, Spiliopoulos A, Swiss Group for Clinical Cancer Research (2007) Multicenter trial of neoadjuvant chemotherapy followed by extrapleural pneumonectomy in malignant pleural mesothelioma. Ann Oncol 18: 1196-1202

Winslow DJ, Taylor HB (1960) Malignant peritoneal mesotheliomas: a clinicopathological analysis of 12 fatal cases. Cancer 13: 127-136

Yan TD, Boyer M, Tin MM, Sim J, Kennedy C, McLean J, Bannon PG, McCaughan BC (2009) Prognostic features of long-term survivors after surgical management of malignant pleural mesothelioma. Ann Thorac Surg 87: $1552-1556$

This work is published under the standard license to publish agreement. After 12 months the work will become freely available and the license terms will switch to a Creative Commons Attribution-NonCommercial-Share Alike 3.0 Unported License. 